\title{
Validation of the post sleep questionnaire for assessing subjects with restless legs syndrome: results from two double-blind, multicenter, placebo-controlled clinical trials
}

\author{
Daniel M Canafax', Abhijeet Bhanegaonkar ${ }^{2}$, Murtuza Bharmal $^{3,4}$ and Michael Calloway ${ }^{5 *}$
}

\begin{abstract}
Background: Because of the subjective nature of Restless Legs Syndrome (RLS) symptoms and the impact of these symptoms on sleep, patient-reported outcomes (PROs) play a prominent role as study endpoints in clinical trials investigating RLS treatments. The objective of this study was to validate a new measure, the Post Sleep Questionnaire (PSQ), to assess sleep dysfunction in subjects with moderate-to-severe RLS symptoms.

Methods: Pooled data were analyzed from two 12-week, randomized, placebo-controlled trials of gabapentin enacarbil $(N=540)$. At baseline and Week 12 , subjects completed the PSQ and other validated health surveys: IRLS Rating Scale, Clinical Global Impression of Improvement (CGI-I), Profile of Mood States (POMS), Medical Outcomes Study Scale-Sleep (MOS-Sleep), and RLS-Quality of Life (RLSQoL). Pooled data were used post hoc to examine the convergent, divergent, known-group validity and the responsiveness of the PSQ.

Results: Convergent validity was demonstrated by significant correlations between baseline PSQ items and total scores of IRLS, POMS, RLSQoL, and the MOS-Sleep Scale ( $p \leq 0.007$ each). Divergent validity was demonstrated through the lack of significant correlations between PSQ items and demographic characteristics. Correlations ( $p<$ 0.0001) between RLS severity groups and PSQ items demonstrated known-group validity. Mean changes in investigator- and subject-rated CGII scores for each PSQ item $(p<0.0001)$ demonstrated the PSQ's responsiveness to patient change as reported by their care provider.

Conclusions: Although these analyses were potentially limited by the use of clinical trial data and not prospective data from a study conducted solely for validation purposes, the PSQ demonstrated robust psychometric properties and is a valid instrument for assessing sleep and sleep improvements in subjects with moderate-to-severe RLS symptoms.
\end{abstract}

Trial Registration: This study analyzed data from two registered trials, NCT00298623 and NCT00365352.

\section{Background}

Restless Legs Syndrome (RLS) is a sensorimotor disorder that can substantially disrupt sleep. It affects $5-10 \%$ of the general population [1], predominantly women [1,2], and has been characterized as chronic in individuals with moderate-to-severe symptoms requiring treatment [3]. The criteria that define RLS include an urge to move the legs due to unpleasant or uncomfortable sensations

\footnotetext{
* Correspondence: michael.o.calloway@gsk.com

${ }^{5}$ GlaxoSmithKline, Research Triangle Park, NC, USA

Full list of author information is available at the end of the article
}

during periods of rest, the relief of symptoms through leg movements, and symptoms that follow a distinct circadian pattern [3]. The onset of RLS symptoms typically begin in the late evening and may persist through the night time hours. Thus, the primary morbidity in RLS is sleep disruption, the major reason patients cite for consulting their physicians $[2,3]$.

Sleep-related problems, such as trouble initiating or maintaining sleep and experiencing disturbed, non-restful or non-refreshing sleep, are more prevalent in patients with RLS than in those without RLS [4]. Nearly

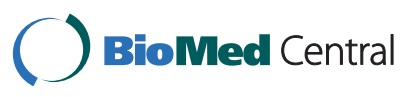

(C) 2011 Canafax et al; licensee BioMed Central Ltd. This is an Open Access article distributed under the terms of the Creative Commons Attribution License (http://creativecommons.org/licenses/by/2.0), which permits unrestricted use, distribution, and reproduction in any medium, provided the original work is properly cited. 
90\% of patients with RLS experience at least 1 sleepassociated symptom and over $40 \%$ of patients identified sleep-associated issues as the most bothersome RLSrelated symptom [5]. Nearly $70 \%$ of patients with twice weekly RLS symptoms needed more than 30 minutes to fall asleep and $60 \%$ had more than 3 awakenings per night. On average, patients with severe RLS symptoms sleep only 4 to 5 hours per night [5].

Because of the subjective nature of RLS symptoms and the impact of these symptoms on sleep, patient-reported outcomes (PROs) play a prominent role as study endpoints in clinical trials investigating RLS treatments. However, for PROs to be credible, they must be subjected to a rigorous inspection of their measurement properties using measurement theory and standard psychometric assessments. While there were several preexisting sleep instruments to choose from (i.e., MOS Sleep Questionnaire) most were limited in their use in RLS research because they were not disease specific, or were more difficult to administer within a clinical trial setting (i.e., clinician-administered). The hope was to be more responsive to the Food and Drug Administration's (FDA) recently emphasized expectations around patient reported outcome measures and the need to demonstrate the validity and reliability of such scales when used to measure endpoints in clinical trials [6].

The Post Sleep Questionnaire (PSQ) is a, 5-item PRO instrument designed to evaluate sleep disturbance in subjects with RLS. This study was a post-hoc evaluation of the validity of the PSQ, Version 2, using data from 2 well-controlled clinical trials in subjects with moderateto-severe RLS $[7,8]$.

\section{Methods}

\section{Data source}

This study used pooled data from two 12-week, multicenter, randomized, double-blind, placebo-controlled clinical trials (XenoPort, Inc. protocols XP052 [ClinicalTrials.gov Identifier NCT00298623] and XP053 [ClinicalTrials.gov Identifier NCT00365352]) that evaluated the efficacy and tolerability of gabapentin enacarbil (GEn) for the treatment of moderate-to-severe primary RLS $[7,8]$. The co-primary endpoints for the $1200 \mathrm{mg}$ and placebo groups in both studies were the reduction in total IRLS score from baseline to Week 12 on the International Restless Legs Scale (IRLS) [9] and the proportion of responders rated by investigators as "very much improved" or "much improved" on the Clinical Global Impression-Improvement [CGI-I] scale) [10]. The secondary endpoints evaluated subject-rated improvements in sleep, mood, and quality of life.

The studies were of similar design. Subjects were randomly assigned for 12 weeks of treatment to GEn 1200 mg or matching placebo (XP052, XP053), with study
XP053 also examining a third treatment group, GEn 600 mg, as a secondary endpoint compared with placebo. These studies demonstrated statistically significant efficacy with both GEn doses compared with placebo for reduction of RLS symptoms and improvements in sleep, mood, and quality of life $[7,8]$.

\section{Study population}

Study methodologies have been published elsewhere $[7,8]$. Briefly, eligible subjects were $\geq 18$ years of age, diagnosed with primary RLS, having RLS symptoms $\geq 15$ nights of the month prior to study enrollement and for $\geq 4$ of 7 consecutive nights in the week prior to their baseline assessment, and had a total RLS severity score of $\geq 15$ (i.e., moderate-to-severe severity). If subjects were receiving RLS treatment at screening, then they must have had a symptom frequency of $\geq 15$ nights per month prior to treatment initiation. A 2-week washout period prior to the baseline assessments was required for dopamine agonists, gabapentin, opioids, and benzodiazepines.

Subjects with non-RLS-related sleep disorders (e.g., sleep apnea), a history of RLS symptom augmentation or early-morning rebound with previous dopamine-agonist treatment, neurological disease or movement disorders other than RLS (e.g., diabetic neuropathy, Parkinson's disease, multiple sclerosis, dyskinesias, and dystonias), or other medical conditions that could confound study results were excluded.

\section{PSQ}

Figure 1 displays the 5 items comprising the PSQ, the sleep domains corresponding to each question, the associated response categories, and the scoring for each. The PSQ was developed to evaluate sleep disturbance in subjects with primary RLS over the past weeks using 4 Likert-type scale questions and 1 quantitative, openended question. The PSQ assesses several single-item sleep domains, including overall sleep quality, overall daytime functioning, frequency of night time RLS symptoms, and RLS-related sleep disturbances and latency. Higher PSQ scores indicate worse sleep.

\section{Validated sleep instruments}

Seven PRO instruments were completed as part of the clinical trials assessments. Five of the instruments were previously validated and were used in the present study to validate the PSQ: 1) IRLS Rating Scale comprises 10 questions that assess symptom severity and frequency on a 40 -point scale $(0=$ no symptom; $40=$ very severe symptoms); subjects were also classified into RLS symptom severity categories using the IRLS total score (mild $=0-10$, moderate $=11-20$, severe $=21-30$, and very severe $\geq 31$ ) [11]; 2) investigator- and subject-rated CGI- 


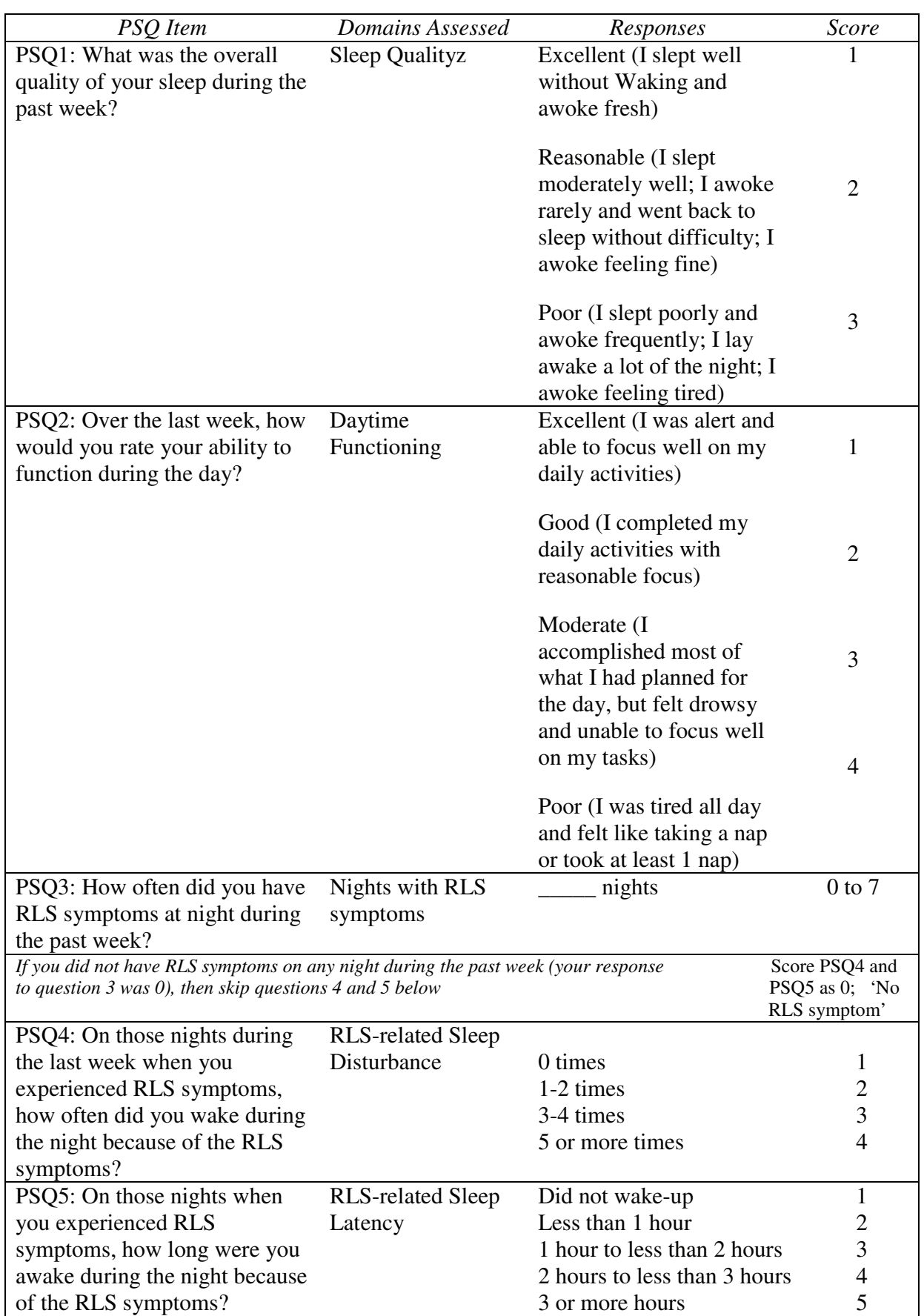

Figure 1 The 5-item PSQ with assessed domains, possible responses, and item scores. Higher scores indicate greater sleep difficulties associated with RLS.

I, evaluates improvements in any disease on a 7-point scale $(1=$ "very much improved"; 7 = "very much worse") [10]; 3) Profile of Mood States (POMS) is a 30item scale that assesses mood in 6 domains and 1 total overall mood score, with higher scores indicating a more negative mood state [12]; 4) Medical Outcomes Study (MOS) Scale-Sleep assesses sleep constructs, including sleep initiation, maintenance, perceived adequacy, somnolence, respiratory impairments, and regularity in subjects with health comorbidities, such as RLS [13-16]; and 5) RLS Quality of Life Questionnaire (RLSQoL), a 100-point scale that assesses the direct impact of RLS on the daily life, emotional well-being, social life, and work-life of the subject, with lower scores 
indicating better quality of life $[17,18]$. The remaining 2 instruments were diaries that provided important subject response information: 1) the 24-hour RLS Record assesses the frequency of RLS symptoms in half-hour increments during a 24-hour period and 2) the 7-Day RLS Symptom Diary assesses the frequency of nightly symptoms over a 1-week period.

\section{Analyses}

Analyses were conducted on pooled data irrespective of treatment assignment, as baseline assessments were used to generate the psychometric indices. Data from 540 subjects were included in these analyses: 220 from XP052 and 320 from XP053. As shown in Table 1, there were no major differences between the 2 study populations at baseline in terms of age, gender, ethnicity, or disease severity.

The following psychometric properties were assessed.

\section{Convergent validity}

Convergent validity, the extent of agreement between 2 scales that measure similar domains or criteria that are linked with the domain of interest, was evaluated using

Table 1 Baseline demographic and characteristics of enrolled subjects from two clinical trials conducted in subjects with primary RLS

\begin{tabular}{|c|c|c|c|}
\hline Characteristic & $\begin{array}{c}\text { XP052 } \\
(n=220)\end{array}$ & $\begin{array}{c}\text { XP053 } \\
(n=320)\end{array}$ & $\begin{array}{c}\text { All } \\
(\mathrm{n}=540)^{2}\end{array}$ \\
\hline \multicolumn{4}{|l|}{ Age } \\
\hline Mean (SD) & $51.5(12.75)$ & $49.3(12.55)$ & $50.2(12.66)$ \\
\hline Female (n, \%) & $131(59.5 \%)$ & $189(59.1 \%)$ & $320(59.3 \%)$ \\
\hline \multicolumn{4}{|l|}{ Race $(n, \%)$} \\
\hline White or Caucasian & $212(96.4)$ & $303(94.7)$ & $515(95.4)$ \\
\hline Black or African-American & $5(2.3)$ & $5(1.6)$ & $10(1.9)$ \\
\hline Other & $3(1.3)$ & $12(3.7)$ & $15(2.7)$ \\
\hline \multicolumn{4}{|l|}{ Ethnicity (n, \%) } \\
\hline Hispanic or Latino & $8(3.6)$ & $25(7.8)$ & $33(6.1)$ \\
\hline Non-Hispanic or Latino & $212(96.4)$ & $295(92.2)$ & $507(93.9)$ \\
\hline \multicolumn{4}{|l|}{ Treatment $(\mathrm{n}, \%)$} \\
\hline 1200 mg & $113(51.4)$ & $111(34.7)$ & $224(41.5)$ \\
\hline 600 mg & 0 & $113(35.3)$ & $113(20.9)$ \\
\hline Placebo & $107(48.6)$ & $96(30.0)$ & $203(37.6)$ \\
\hline \multicolumn{4}{|l|}{ RLS Severity $(n, \%)^{1}$} \\
\hline Mild & 0 & 0 & 0 \\
\hline Moderate & $82(37.3)$ & $102(31.9)$ & $184(34.1)$ \\
\hline Severe & $121(55.0)$ & $193(60.3)$ & $314(58.1)$ \\
\hline Very severe & $17(7.7)$ & $25(7.8)$ & $42(7.8)$ \\
\hline
\end{tabular}

RLS, Restless Legs Syndrome; SD, standard deviation.

${ }^{1}$ RLS Disease Severity based on International Restless Legs Rating Scale Total Score, where mild $=0-10$, moderate $=11-20$, severe $=21-30$, and very severe $>30$.

${ }^{2}$ In the original clinical trials; there were a total of 544 subjects. In this study we used the Post Sleep Questionnaire (PSQ) validation sample, which includes only those who completed the PSQ at Baseline $(\mathrm{N}=540)$ and Week $12(\mathrm{~N}=$ 451). the nonparametric Spearman-rank correlation coefficient. Convergent validity is accepted when the correlation estimates are in the correct theoretical direction [19] and are statistically significant. If correlation coefficients are statistically significant, Cohen [20] describes correlations of 0.1 as small, 0.3 as medium, and $\geq 0.5$ as large convergence. Convergent validity for the PSQ was determined by correlating the PSQ item scores with the total scores from the IRLS, RLSQoL, and POMS, and the 4 individual domain scores of the MOS-Sleep scale.

Individual PSQ item scores were also correlated with similar items from daily diaries that captured RLS-related symptoms and sleep: PSQ Item 3 (nights with RLS symptoms) score and nights with RLS symptoms score from the 7-Day RLS Symptom Diary, PSQ Item 4 (RLS-related sleep disturbance) with number of RLS-related awakenings score from the 24-Hour RLS Symptom Diary, and PSQ Item 5 (RLS-related sleep latency) with the RLS-related sleep latency score from the 24-Hour RLS Record.

\section{Divergent validity}

An instrument demonstrates divergent validity when it shows a lack of statistical association with other instruments or related variables (e.g., demographic characteristics) unrelated to the focus instrument. This study was limited in the choice of instruments to assess divergent validity because it utilized only the instruments included in the clinical trials $[7,8]$ that were used to measure the effects of RLS treatment. To demonstrate divergent validity of the PSQ, we assessed correlations between the baseline PSQ item scores and three demographic variables: ethnicity, race, and gender. Because there was no theoretical basis to expect a relationship between sleep problems and these demographic variables, a lack of correlation would demonstrate that subjects with different demographic characteristics do not interpret the PSQ items differently. Cramer's V statistic was used to assess their associations [21], because this involved correlating a nominally scaled variable (i.e., $0=$ Male, $1=$ Female) with continuous variables. Cramer's V estimates range from 0 to 1 , with low scores indicating poor association and demonstrating divergent validity.

\section{Known-group validity}

Known-group validity, or predictive validity, is the ability of a scale or scale items to statistically discriminate respondents in ways expected (predicted) as a result of independent assessments. The known groups in the current study were based on RLS symptom severity, as determined by the IRLS total score. Sleep qualities measured by the PSQ are expected to be most pronounced for persons with severe symptoms. Baseline PSQ scores were compared across severity groups using the Kruskal-Wallis test [22]. 


\section{Responsiveness}

Responsiveness means that the PSQ item scores will change in direction and magnitude with changes experienced by the responders. In this case, responsiveness was demonstrated if relationships between changes in the investigator- and subject-rated CGI-I assessments and changes in PSQ scores over time were in the same direction and statistically significant [15]. Change from baseline in individual PSQ items were compared with subject symptom changes as measured by the CGI-I using the Kruskal-Wallis test. Among all subjects in the clinical trials $[7,8]$, only a few experienced worsening of symptoms over time; as a result, the responsiveness analysis was conducted by re-categorizing subjects reporting 'minimally worse', 'much worse' and 'very much worse' into 1 category of 'worse'. Guyatt's statistic, a measure of test-retest reliability or responsiveness to change, which is the ratio of the mean change for each category divided by the standard deviation for the no change group, was estimated. An instrument with an absolute value of $\geq 0.20$ for Guyatt's statistic has acceptable responsiveness and a value of $\geq 1.00$ is considered highly responsive to change [23,24].

\section{Results}

\section{Subject characteristics}

Of 544 total subjects, 540 and 451 completed the PSQ at Baseline and Week 12, respectively, and were included in the analysis. Table 1 shows that the baseline mean age of subjects was approximately 50 years, most subjects were non-Hispanic, white, and female. About $92 \%$ had moderate or severe RLS symptoms and $8 \%$ had very severe symptoms.

\section{PSQ results}

The mean scores for PSQ items indicate that most subjects improved over the 12-week study, and most of the improvements occurred by Week 4 (Table 2). For sleep quality, the percentage of subjects reporting their sleep quality as "excellent" increased by approximately $20 \%$ by Week 12. Daytime functioning showed similar positive gains, with 4.5 times as many subjects reporting their daytime functioning as "excellent" at Week 12 compared with baseline. Similar improvements in frequency of nighttime RLS symptoms, RLS-related sleep disturbances and sleep latency over the 12 weeks were observed.

\section{Convergent validity}

Table 3 shows the Spearman rank correlation coefficients and the probability of each PSQ item based on the total scores of the IRLS, RLSQoL, and POMS. All correlations between the IRLS total score and each PSQ item were statistically significant, ranging from 0.25 to 0.49 ( $p>0.0001$, each). The strength of the associations showed moderate to moderately high convergence. The overall POMS total score had statistically significant correlations with the PSQ items, except for the item "nights with RLS symptoms". The correlations ranged from 0.04 to 0.48 . All but 1 of the correlations were small in size; daytime functioning was moderately high. For the individual POMS items, 22 of 35 correlations were statistically significant ( $p<0.05$ each; data not shown). The correlations between the RLSQoL total score and the PSQ items were also statistically significant. The correlation coefficients ranged from -0.12 to -0.57 ( $p<0.01$ each). The convergence was large for daytime functioning, moderate for sleep quality, and small for all others.

The correlations between the MOS-Sleep scale domains and the PSQ items are provided in Table 4. The correlation coefficients ranged from -0.46 to 0.49 ; 18 of 20 correlations were statistically significant $(\mathrm{p}<$ 0.02 ). Of the 20 correlations, 9 had moderate to moderately large coefficients. Moderately high convergence was seen between the PSQ sleep quality item and the MOS sleep disturbance domain (higher sleep disturbance, lower sleep quality) and sleep adequacy (higher sleep quality, higher sleep adequacy), between PSQ daytime functioning and MOS daytime somnolence domain (worse functioning, worse somnolence), between PSQ sleep latency and MOS sleep disturbance domain (higher sleep latency, higher sleep disturbance). The correlations of the PSQ item nights with RLS symptoms were statistically significant with MOS sleep domains, but showed small convergence with MOS sleep disturbance, adequacy and quantity domains.

The 7-day RLS Symptom Diary significantly correlated with the PSQ item \#3 nights with RLS symptoms ( $\mathrm{r}=$ 0.47; $\mathrm{p}<0.0001$; data not shown). The correlation between the 24-hour RLS Symptom Record Diary and the PSQ items RLS-related sleep disturbance and RLS-related sleep latency were 0.17 and 0.27 , respectively ( $\mathrm{p}<0.0001$, both).

\section{Divergent validity}

None of the correlation estimates from Cramer's V for any PSQ item baseline score across the 3 demographic variables (i.e., race, gender and ethnicity) were larger than 0.13 (data not shown) and none approached statistical significance, thereby demonstrating divergent validity. For race, the correlation estimates ranged from 0.05 for sleep latency to 0.13 for sleep disturbance. The respective estimates for ethnicity ranged from 0.02 to 0.07 , and for gender, the range was 0.05 to 0.12 .

\section{Known-group validity}

Positive and statistically significant differences ( $\mathrm{p}<$ 0.0001, each) were found between baseline PSQ scores and the RLS severity groups moderate, severe, and very severe (Table 5). The estimates were linear across the severity groups with very severe RLS subjects having 
Table 2 Subject responses and mean scores for PSQ items

\begin{tabular}{|c|c|c|c|c|}
\hline \multicolumn{5}{|l|}{ Overall sleep quality } \\
\hline Excellent, $\mathrm{n}(\%)$ & $3(0.6)$ & $98(20.1)$ & $78(16.6)$ & $91(20.2)$ \\
\hline Reasonable, n (\%) & $209(38.7)$ & $294(60.2)$ & $293(62.2)$ & $279(61.9)$ \\
\hline Poor, n (\%) & $328(60.7)$ & $96(19.7)$ & $100(21.2)$ & $81(18.0)$ \\
\hline Mean PSQ score (SD) & $2.602(0.501)$ & $1.996(0.631)$ & $2.047(0.614)$ & $1.978(0.618)$ \\
\hline \multicolumn{5}{|l|}{ Daytime functioning } \\
\hline Excellent, n (\%) & $35(6.5)$ & $146(29.9)$ & $163(34.6)$ & $159(35.3)$ \\
\hline Good, n (\%) & $240(44.4)$ & $238(48.8)$ & $222(47.1)$ & $220(48.8)$ \\
\hline Moderate, n (\%) & $230(42.6)$ & 95 (19.5) & $80(17.0)$ & $63(14.0)$ \\
\hline Poor, n (\%) & $35(6.5)$ & $9(1.8)$ & $6(1.3)$ & $9(2.0)$ \\
\hline Mean PSQ score (SD) & $2.491(0.714)$ & $1.932(0.751)$ & $1.849(0.738)$ & $1.827(0.737)$ \\
\hline \multicolumn{5}{|c|}{ Frequency of nighttime RLS symptoms } \\
\hline 0 & 0 & $83(17.0)$ & $99(21.0)$ & $109(24.2)$ \\
\hline 1 & $9(1.7)$ & $144(29.5)$ & $133(28.2)$ & $126(27.9)$ \\
\hline 2 & $46(8.5)$ & $107(21.9)$ & $103(21.9)$ & $77(17.1)$ \\
\hline 3 & $187(34.6)$ & $61(12.5)$ & $57(12.1)$ & $67(14.9)$ \\
\hline 4 & $298(55.2)$ & $93(19.1)$ & 79 (16.8) & $72(16.0)$ \\
\hline Mean PSQ score (SD) & $3.433(0.719)$ & $1.871(1.360)$ & $1.754(1.363)$ & $1.705(1.397)$ \\
\hline \multicolumn{5}{|c|}{ Frequency of RLS-related sleep disturbance } \\
\hline No RLS symptoms & 0 & $83(17.0)$ & $99(21.0)$ & $109(24.2)$ \\
\hline 0 times & $59(10.9)$ & $135(27.7)$ & $111(23.6)$ & $115(25.5)$ \\
\hline 1-2 times & $262(48.5)$ & $203(41.6)$ & $205(43.5)$ & $184(40.8)$ \\
\hline 3-4 times & $163(30.2)$ & $49(10.0)$ & $48(10.2)$ & $36(8.0)$ \\
\hline$\geq 5$ times & $56(10.4)$ & $18(3.7)$ & $8(1.7)$ & $7(1.6)$ \\
\hline Mean PSQ score (SD) & $2.400(0.817)$ & $1.557(1.006)$ & $1.480(0.989)$ & $1.373(0.986)$ \\
\hline \multicolumn{5}{|c|}{ RLS-related sleep latency (time awake) } \\
\hline No RLS symptoms & 0 & $83(17.0)$ & $99(21.0)$ & $109(24.2)$ \\
\hline Did not wake-up & $59(10.9)$ & $135(27.7)$ & $111(23.6)$ & $115(25.5)$ \\
\hline$<1$ hour & $240(44.4)$ & $176(36.1)$ & $180(38.2)$ & $160(35.5)$ \\
\hline $1-<2$ hours & $133(24.6)$ & $67(13.7)$ & $57(12.1)$ & $45(10.0)$ \\
\hline $2-<3$ hours & $74(13.7)$ & $12(2.5)$ & $18(3.8)$ & $12(2.7)$ \\
\hline$\geq 3$ hours & $34(6.3)$ & $15(3.1)$ & $6(1.3)$ & $10(2.2)$ \\
\hline Mean PSQ score (SD) & $2.600(1.055)$ & $1.662(1.165)$ & $1.580(1.136)$ & $1.481(1.167)$ \\
\hline
\end{tabular}

PSQ, Post Sleep Questionnaire; RLS, Restless Legs Syndrome; SD, standard deviation.

${ }^{1} \mathrm{All}$ responses were based on experiences during the previous week.

Higher PSQ scores correspond to worse symptoms.

Table 3 Convergent validity: PSQ item correlations at baseline with IRLS, POMS, and RLSQoL total scores

\begin{tabular}{lccc}
\hline PSQ item & $\begin{array}{c}\text { IRLS total score } \\
(\mathbf{n}=\mathbf{5 4 0})\end{array}$ & $\begin{array}{c}\text { POMS overall mood score } \\
(\mathbf{n}=\mathbf{5 3 9})\end{array}$ & $\begin{array}{c}\text { RLSQoL total score } \\
(\mathbf{n}=\mathbf{5 4 0})\end{array}$ \\
\cline { 2 - 4 } & Correlation $(\mathbf{p}$-value) & Correlation ( $\mathbf{p}$-value) & Correlation $(\mathbf{p}$-value $)$ \\
\hline Sleep quality & $0.4635(<0.0001)$ & $0.2319(<0.0001)$ & $-0.2986(<0.0001)$ \\
\hline Daytime functioning & $0.4890(<0.0001)$ & $0.4818(<0.0001)$ & $-0.5663(<0.0001)$ \\
\hline Nights with RLS symptoms & $0.2509(<0.0001)$ & $0.0388(0.3690)$ & $-0.1154(0.0073)$ \\
\hline RLS-related sleep disturbance & $0.3186(<0.0001)$ & $0.1174(0.0063)$ & $-0.2371(<0.0001)$ \\
\hline RLS-related sleep latency & $0.3725(<0.0001)$ & $0.1205(0.0051)$ & $-0.2870(<0.0001)$ \\
\hline
\end{tabular}

IRLS, International Restless Legs Rating Scale; POMS, Profile of Mood States; PSQ, Post Sleep Questionnaire; RLSQoL, Restless Legs Syndrome Quality of Life Questionnaire.

Spearman Correlation coefficients.

Higher PSQ scores correspond to worse RLS symptoms.

Higher IRLS Total scores correspond to higher severity of restless leg syndrome symptoms.

Higher POMS scores correspond to increased negative mood affect.

Higher RLS Quality of life scores correspond to better quality of life. 
Table 4 Convergent validity: PSQ items and MOS Sleep domains at baseline

\begin{tabular}{lcccc}
\hline PSQ item & \multicolumn{2}{c}{ MOS Sleep Domain Scores } \\
\cline { 2 - 5 } & $\begin{array}{c}\text { Daytime somnolence } \\
\mathbf{n}=\mathbf{5 4 0}\end{array}$ & $\begin{array}{c}\text { Sleep disturbance } \\
\mathbf{n}=\mathbf{5 4 0}\end{array}$ & $\begin{array}{c}\text { Sleep adequacy } \\
\mathbf{n}=\mathbf{5 4 0}\end{array}$ & $\begin{array}{c}\text { Sleep quantity } \\
\mathbf{n}=\mathbf{5 3 9}\end{array}$ \\
\cline { 2 - 6 } & $\begin{array}{c}\text { Correlation } \\
(\mathbf{p} \text {-value })\end{array}$ & $\begin{array}{c}\text { Correlation } \\
(\mathbf{p} \text {-value })\end{array}$ & $\begin{array}{c}\text { Correlation } \\
(\mathbf{p} \text {-value })\end{array}$ & $\begin{array}{c}\text { Correlation } \\
(\mathbf{p} \text {-value })\end{array}$ \\
\hline Sleep quality & $0.1856(<0.0001)$ & $0.4878(<0.0001)$ & $-0.4635(<0.0001)$ & $-0.3827(<0.0001)$ \\
\hline Daytime functioning & $0.4290(<0.0001)$ & $0.3027(<0.0001)$ & $-0.4084(<0.0001)$ & $-0.2287(<0.0001)$ \\
\hline Nights with RLS symptoms & $0.0458(0.2881)$ & $0.1025(0.0172)$ & $-0.1537(0.0003)$ & $-0.1207(0.0050)$ \\
\hline RLS-related sleep disturbance & $0.1369(0.0014)$ & $0.3158(<0.0001)$ & $-0.2188(<0.0001)$ & $-0.2742(<0.0001)$ \\
\hline RLS-related sleep latency & $0.0633(0.1420)$ & $0.4290(<0.0001)$ & $-0.2083(<0.0001)$ & $-0.3798(<0.0001)$ \\
\hline
\end{tabular}

MOS, Medical Outcomes Study; PSQ, Post Sleep Questionnaire; RLS, restless legs syndrome.

Spearman Correlation coefficients.

Higher PSQ scores correspond to worse symptoms.

Higher MOS Daytime Somnolence scores and MOS Sleep Disturbance scores correspond to worse symptoms.

Higher MOS Sleep Adequacy scores and MOS Sleep Quantity scores correspond to better symptoms.

worse PSQ scores than subjects with severe RLS and subjects with severe RLS having worse PSQ scores than subjects with moderate RLS.

\section{Responsiveness}

The mean change in PSQ scores from baseline to Week 12 indicate that improvements in sleep were achieved and scores were significantly improved across each of the investigator- and subject-rated CGI-I categories (Tables 6 and 7, respectively). The largest change was among those subjects judged by the clinician as being "very much improved" followed by "much improved", "minimally improved", "no change", and finally "worse." The magnitude of the effect size for change in PSQ scores from baseline also followed the above linear

Table 5 Known-group validity PSQ items and RLS disease severity as assessed by IRLS total score at baseline

\begin{tabular}{lcccc}
\hline $\begin{array}{l}\text { PSQ item score, mean } \\
\text { (SD) }\end{array}$ & \multicolumn{3}{c}{ RLS disease severity } & $\begin{array}{c}\text { p- } \\
\text { value }\end{array}$ \\
\cline { 2 - 6 } & $\begin{array}{c}\text { Moderate } \\
\mathbf{n = 1 8 4}\end{array}$ & $\begin{array}{c}\text { Severe } \\
\mathbf{n}=\mathbf{3 1 4}\end{array}$ & $\begin{array}{c}\text { Very } \\
\text { Severe } \\
\mathbf{n}=\mathbf{4 2}\end{array}$ & \\
\hline Sleep quality & 2.342 & 2.710 & 2.929 & $<0.0001$ \\
& $(0.509)$ & $(0.454)$ & $(0.261)$ & \\
\hline Daytime functioning & 2.125 & 2.611 & 3.190 & $<0.0001$ \\
& $(0.619)$ & $(0.651)$ & $(0.740)$ & \\
\hline Nights with RLS & 3.228 & 3.535 & 3.571 & $<0.0001$ \\
symptoms & $(0.777)$ & $(0.664)$ & $(0.668)$ & \\
\hline RLS-related sleep & 2.136 & 2.465 & 3.071 & $<0.0001$ \\
disturbance & $(0.774)$ & $(0.792)$ & $(0.712)$ & \\
\hline RLS-related sleep latency & 2.190 & 2.720 & 3.500 & $<0.0001$ \\
& $(0.869)$ & $(1.035)$ & $(1.174)$ & \\
\hline
\end{tabular}

IRLS, International Restless Legs Rating Scale; PSQ, Post Sleep Questionnaire; RLS, Restless Legs Syndrome; SD, standard deviation.

Higher PSQ scores correspond to worse symptoms.

p-value is based on Kruskal-Wallis test.

RLS Disease Severity based on IRLS Total Score, where mild $=0-10$, moderate $=11-20$, severe $=21-30$, and very severe $>30$. order (data not shown). The magnitude of Guyatt's statistic was moderate to large, ranging from 0.00 to 3.46 among improved subjects. Of the 50 coefficients, 7 did not meet the acceptable cutpoint of 0.20 or greater and all but 1 of the 7 was in the "worse" category. Additionally, 11 of the 50 coefficients were $>1$, indicating a highly responsive measure.

\section{Discussion}

This post hoc psychometric evaluation of an investigator-developed PRO instrument used data from 2 randomized, double-blind, placebo-controlled trials conducted in subjects with moderate-to-severe primary RLS to examine the validity of the PSQ in assessing RLS-related sleep disturbance and treatment improvements. The parent studies indicated that the PSQ scores showed improved sleep in subjects with RLS symptoms who received active RLS treatment compared with placebo $[7,8]$.

To verify the validity of the PSQ, several measurement properties were evaluated. The PSQ's convergent validity was estimated using correlations between the overall RLS symptom impact score, as assessed with the IRLS, and the individual PSQ items. These correlation estimates were all statistically significant and positive (i.e., worse symptom impact with worse sleep status). All PSQ items scores had moderate convergence with overall RLS symptom impact, except for the PSQ item "nights with RLS symptoms", which had a lower convergence.

Convergent validity was also assessed using the MOS Sleep Scale. Nearly half of the correlations with the MOS-Sleep Scale sleep domains showed moderate to moderately high convergence. Two PSQ items, nights with RLS symptoms and RLS-related sleep latency, showed little convergence with the MOS daytime somnolence domain. The PSQ sleep quality domain had 
Table 6 Responsiveness: mean change from baseline in PSQ item scores and Guyatt's statistic by investigator-rated CGI-I at Week 12

\begin{tabular}{|c|c|c|c|c|c|c|}
\hline \multirow[b]{2}{*}{ PSQ domains } & \multicolumn{5}{|c|}{ Investigator-rated CGI-I } & \multirow[b]{2}{*}{ p-value } \\
\hline & $\begin{array}{c}\text { Very Much } \\
\text { Improved } \\
\mathrm{n}=173\end{array}$ & $\begin{array}{c}\text { Much Improved } \\
n=126\end{array}$ & $\begin{array}{c}\text { Minimally Improved } \\
n=64\end{array}$ & $\begin{array}{l}\text { No Change } \\
n=73\end{array}$ & $\begin{array}{c}\text { Worsen } \\
n=7\end{array}$ & \\
\hline \multicolumn{7}{|l|}{ Sleep quality } \\
\hline Mean delta (SD) & $-0.92(0.74)$ & $-0.67(0.63)$ & $-0.34(0.60)$ & $-0.14(0.56)$ & $0.14(0.38)$ & $<0.0001$ \\
\hline Guyatt's statistic & 1.64 & 1.19 & 0.61 & 0.24 & 0.25 & \\
\hline \multicolumn{7}{|l|}{ Daytime functioning } \\
\hline Mean delta (SD) & $-1.03(0.91)$ & $-0.62(0.77)$ & $-0.34(0.76)$ & $-0.15(0.78)$ & $0.14(0.38)$ & $<0.0001$ \\
\hline Guyatt's statistic & 1.33 & 0.80 & 0.44 & 0.19 & 0.18 & \\
\hline \multicolumn{7}{|c|}{ Nights with RLS symptoms } \\
\hline Mean delta (SD) & $-2.71(1.03)$ & $-1.75(1.20)$ & $-0.97(1.10)$ & $-0.26(0.94)$ & $0.57(0.53)$ & $<0.0001$ \\
\hline Guyatt's statistic & 2.87 & 1.86 & 1.03 & 0.28 & 0.61 & \\
\hline \multicolumn{7}{|c|}{ RLS-related sleep disturbance } \\
\hline Mean delta (SD) & $-1.72(1.14)$ & $-0.80(0.96)$ & $-0.58(0.83)$ & $-0.25(0.95)$ & $-1.14(1.07)$ & $<0.0001$ \\
\hline Guyatt's statistic & 1.81 & 0.84 & 0.61 & 0.26 & 1.20 & \\
\hline \multicolumn{7}{|c|}{ RLS-related sleep latency } \\
\hline Mean delta (SD) & $-1.82(1.47)$ & $-0.80(1.18)$ & $-0.69(1.40)$ & $-0.19(1.09)$ & $-1.29(0.95)$ & $<0.0001$ \\
\hline Guyatt's statistic & 1.67 & 0.74 & 0.63 & 0.18 & 1.18 & \\
\hline
\end{tabular}

CGI-I, Clinical Global Impression-Improvement, Investigator-rated; PSQ = Post Sleep Questionnaire; SD, standard deviation.

Higher PSQ scores correspond to worse symptoms.

Mean delta is change from baseline to Week 12.

p-value is based on Kruskal-Wallis test.

Guyatt's statistic is the ratio of the mean change score for each category of subjects divided by the standard deviation for the no change group.

Table 7 Responsiveness: mean change from baseline in PSQ item scores, effect size, and Guyatt's statistic by subjectrated CGI-I at Week 12

\begin{tabular}{|c|c|c|c|c|c|c|}
\hline \multirow[b]{2}{*}{ PSQ domains } & \multicolumn{5}{|c|}{ Subject-rated Clinical Global Impression of Change } & \multirow[b]{2}{*}{ p-value } \\
\hline & $\begin{array}{c}\text { Very Much } \\
\text { Improved } \\
n=175\end{array}$ & $\begin{array}{c}\text { Much Improved } \\
n=130\end{array}$ & $\begin{array}{l}\text { Minimally Improved } \\
\qquad n=61\end{array}$ & $\begin{array}{c}\text { No Change } \\
n=65\end{array}$ & $\begin{array}{l}\text { Worse } \\
n=15\end{array}$ & \\
\hline \multicolumn{7}{|l|}{ Sleep quality } \\
\hline Mean delta (SD) & $-0.92(0.77)$ & $-0.68(0.60)$ & $-0.31(0.59)$ & $-0.14(0.56)$ & $0.00(0.38)$ & $<0.0001$ \\
\hline Guyatt's statistic & 1.66 & 1.23 & 0.56 & 0.25 & 0.00 & \\
\hline \multicolumn{7}{|l|}{ Daytime functioning } \\
\hline Mean delta (SD) & $-1.01(0.92)$ & $-0.68(0.77)$ & $-0.33(0.60)$ & $-0.05(0.80)$ & $-0.13(0.74)$ & $<0.0001$ \\
\hline Guyatt's statistic & 1.27 & 0.85 & 0.41 & 0.06 & 0.17 & \\
\hline \multicolumn{7}{|c|}{ Nights with RLS symptoms } \\
\hline Mean selta (SD) & $-2.74(0.99)$ & $-1.70(1.22)$ & $-0.93(1.06)$ & $-0.25(0.79)$ & $0.00(1.41)$ & $<0.0001$ \\
\hline Guyatt's statistic & 3.46 & 2.15 & 1.18 & 0.31 & 0.00 & \\
\hline \multicolumn{7}{|c|}{ RLS-related sleep disturbance } \\
\hline Mean delta (SD) & $-1.67(1.15)$ & $-0.89(1.01)$ & $-0.48(0.74)$ & $-0.32(0.94)$ & $-0.47(1.19)$ & $<0.0001$ \\
\hline Guyatt's statistic & 1.78 & 0.95 & 0.51 & 0.34 & 0.50 & \\
\hline \multicolumn{7}{|c|}{ RLS-related sleep latency } \\
\hline Mean delta (SD) & $-1.82(1.41)$ & $-0.86(1.35)$ & $-0.38(1.20)$ & $-0.32(1.00)$ & $-0.73(1.44)$ & $<0.0001$ \\
\hline Guyatt's statistic & 1.82 & 0.86 & 0.38 & 0.32 & 0.73 & \\
\hline
\end{tabular}

CGI-I, Clinical Global Impression-Improvement, subject-rated; SD = Standard Deviation

Mean delta is change from baseline to Week 12

p-value is based on Kruskal-Wallis test

Effect size based on Cohen's $d$ is the difference in the mean score/pooled standard deviation.

Guyatt's statistic is the ratio of the mean change score for each category of subjects divided by the standard deviation for the no change group. 
sufficient convergence with the MOS sleep disturbance, sleep adequacy and sleep quantity domains. The PSQ daytime functioning item had sufficient convergence with all the MOS domains. The PSQ item, RLS-related sleep latency, had sufficient convergence with MOS sleep domains, except daytime somnolence. Taken together, these data suggest that the PSQ items had adequate convergence with the most pertinent MOS sleep domains.

Validity can also be shown via divergence with scales intended to measure other concepts. We found no strong associations across the 3 demographic variables of race, ethnicity and gender with the PSQ items. While demographics are not traditionally used for assessing divergent validity, we were limited to using the data collected in the trials. Given that, these findings clearly and robustly demonstrate that the PSQ results do not include systematic measurement errors that could be associated with personal attributes.

The PSQ results showed a consistent and robust ability to discriminate between RLS severity groups in a known-group validity analysis. All estimates were linear across the severity groups with increasingly worse sleep outcomes found in progressively worse symptom groups.

The PSQ was found to provide reliable results; for example, the PSQ was responsive to treatment differences over 12 weeks, and the findings were consistent regardless of whether the investigator or the subject rated the improvement, as indicated by the clinician and the patient rated CGI-Is. Further, the changes were seen regardless of treatment assignment, indicating that the PSQ is sensitive to small clinical changes over the course of treatment. Guyatt's statistic, an indication of responsiveness to change, was acceptably strong in all responder categories that indicated change and comparatively weaker in groups that indicated no change or worse change.

The post hoc nature of this study posed some challenges. Analyses were confined to the instruments collected as part of the clinical trials and were not included for the purposes of conducting a validation study. Thus, some aspects of the instruments used to validate the PSQ may not have been ideal. For example, items on some instruments are not directly related to sleep or are confounded by sleep. Finally, the recall periods varied among the instruments and some instruments were not specifically designed for RLS.

\section{Conclusions}

The PSQ demonstrated acceptable measurement properties of convergent validity, divergent validity, and known-group validity. PSQ scores were also reliable in terms of being responsive to change in symptoms. The PSQ is, therefore, a psychometrically valid instrument for assessing sleep among RLS subjects in clinical trial settings.

\section{Acknowledgements}

Editorial support in the form of production of manuscript first draft, editorial suggestions to draft versions of this paper, assembling tables and figures, collating author comments, copyediting, fact checking, and referencing was provided by Tracey Fine, MS, ELS of Fine Biomedical Publications, Inc. (funded by GlaxoSmithKline). The original clinical trials (XenoPort, Inc. protocol XP052 [ClinicalTrials.gov Identifier NCT00298623] and XP053 [ClinicalTrials.gov Identifier NCT00365352]) were funded and conducted by XenoPort, Inc., Santa Clara, CA, USA. Research funding for design and conduct of this validation study of the Post Sleep Questionnaire was funded by GlaxoSmithKline, Research Triangle Park, NC. The clinical trial information reported in this manuscript is consistent with that on ClinicalTrials.gov. Preparation, review, and approval of the manuscript were sponsored by GlaxoSmithKline. This publication went through all required reviews and approvals by the Publication Team according to GlaxoSmithKline Policy 408 and Standard Operating Procedure 27.

\section{Author details}

${ }^{1}$ XenoPort, Inc., Santa Clara, CA, USA. ${ }^{2}$ West Virginia University School of Pharmacy, Morgantown, WV, USA. ${ }^{3}$ Current Address: GlaxoSmithKline R\&D China, Shanghai, China. ${ }^{4}$ Previous Address: Quintiles, Rockville, MD, USA.

${ }^{5}$ GlaxoSmithKline, Research Triangle Park, NC, USA.

\section{Authors' contributions}

All the authors contributed to the manuscript and have read and approved the final version.

DMC: project management, study design, execution, medical monitoring, analysis, and primary author. AJB: psychometric design, contributing author. MFB: study design, psychometric design and analysis, project management, contributing author. MOC: study design, psychometric design and data analysis, project management, contributing author.

\section{Competing interests}

DMC is an employee of XenoPort, Inc. where the RLS clinical studies were designed and conducted. AJB worked on this project as a graduate intern from West Virginia University at GlaxoSmithKline, Research Triangle Park, NC. MFB was a full-time employee of Quintiles, Inc., (the company that GlaxoSmithKline sponsored to conduct the psychometric research) at the time this study was conducted. MOC is a full-time employee of GlaxoSmithKline, Research Triangle Park, NC.

Received: 10 August 2010 Accepted: 28 April 2011 Published: 28 April 2011

\section{References}

1. Hening WA, Allen RP, Washburn M, Lesage SR, Earley CJ: The four diagnostic criteria for Restless Legs Syndrome are unable to exclude confounding conditions ("mimics"). Sleep Med 2009, 10:976-981.

2. Thomas K, Watson CB: Restless legs syndrome in women: a review. J Women's Health 2008, 17:859-868.

3. Allen RP, Picchietti D, Hening WA, Trenkwalder C, Walters AS, Montplaisi J: Restless legs syndrome: diagnostic criteria, special considerations, and epidemiology. A report from the restless legs syndrome diagnosis and epidemiology workshop at the National Institutes of Health. Sleep Med 2003, 4:101-119.

4. Ulfberg J, Nystrom B, Carter N, Edling C: Prevalance of Restless Legs Syndrome among men aged 18 to 64 years of age: An assessment with somatic disease and neuropsychiatric symptoms. Mov Disord 2001, 16:1159-1163.

5. Hening W, Walters AS, Allen RP, Montplaisir J, Myers A, Ferini-Strambi L: Impact, diagnosis and treatment of restless legs syndrome (RLS) in a primary care population: The REST (RLS epidemiology, symptoms, and treatment) primary care study. Sleep Med 2004, 5:237-246.

6. United States Food and Drug Administration: Guidance for industry. Patient-reported outcome measures: Use in medical product 
development. 2009 [http://www.fda.gov/downloads/Drugs/ GuidanceComplianceRegulatoryInformation/Guidances/UCM071975.pdf].

7. Kushida CA, Becker PM, Ellenbogen AL, Canafax DM, Barrett RW, XP052 Study Group: Randomized, double-blind, placebo-controlled study of XP13512/GSK1838262 in patients with RLS. Neurology 2009, 72:439-446.

8. Lee D, Ziman R, Perkins AT, Poceta JS, Walters A, Barrett R: Randomized, double-blind, placebo-controlled study to assess the efficacy and tolerability of gabapentin enacarbil in subjects with restless legs syndrome (RLS) [abstract]. Neurology 2009, 72(Suppl 3):A337.

9. Walters AS, LeBroca C, Dhar A, Hening W, Rosen R, Allen RP, Trenkwalder C: Validation of the International Restless Legs Syndrome Study Group rating scale for restless legs syndrome. Sleep Med 2003, 4:121-132.

10. Guy W: Clinical global impressions (CGI). Early Clinical Drug Evaluation (ECDEU) Assessment Manual for Psychopharmacology. Revised edition. U.S. Department of Health, Education, and Welfare, National Institute of Mental Health, Psychopharmacology Research Branch: Rockville, MD; 1976, 2172-2222.

11. Hening WA, Allen RP: Restless legs syndrome (RLS): the continuing development of diagnostic standards and severity measures. Sleep Medicine 2003, 4:95-97.

12. Curran SL, Andrykowski MA, Studts JL: Short form of the Profile of Mood States: Psychometric information. Psychology Assessment 1995, 7:80-83.

13. Hays RD, Stewart AL: Sleep Measures. In Measuring functioning and wellbeing: the Medical Outcomes Study approach. Edited by: Stewart AL, Ware JE. Durham, NC: Duke University Press; 1992:235-259.

14. Hays RD, Martin SA, Sesti AM, Spritzer KL: Psychometric properties of the Medical Outcomes Study sleep measure. Sleep Med 2005, 6:41-44.

15. Hays R, Revicki DA: Reliability and validity (including responsiveness). In Assessing Quality of Life in Clinical Trials.. 2 edition. Edited by: Fayers P, Hays R. New York: Oxford University Press; 2005:25-39.

16. Allen RP, Kosinski M, Hill-Zabala CE, Calloway MO: Psychometric evaluation and tests of validity of the Medical Outcomes Study 12-item Sleep Scale in restless legs syndrome. Sleep Med 2009, 10:531-539.

17. Abetz L, Arbuckle R, Allen RP, Mavraki E, Kirsch J: The reliability, validity and responsiveness of the Restless Legs Syndrome Quality of Life questionnaire (RLSQoL) in a trial population. Health Qual Life Outcomes 2005, 3:79.

18. Abetz L, Vallow SM, Kirsch J, Allen RP, Washburn T, Earley CJ: Validation of the Restless Legs Syndrome Quality of Life questionnaire. Value Health 2005, 8:157-167.

19. Carmines EG, Zeller RA: Reliability and validity assessment. Sage University Paper Series on Quantitative Applications in the Social Sciences, 07-017 Newbury Park, CA: Sage; 1979.

20. Cohen J: Statistical power analysis for the behavioral sciences Hillsdale: Lawrence Erlbaum Associates; 1988.

21. Cramér H: Mathematical Methods of Statistics Princeton, NJ: Princetown University Press; 1999.

22. Kruskal $W$, Wallis $K$ : Use of ranks in one-criterion variance analysis. J Am Stat Assoc 1952, 47:583-621.

23. Guyatt GH, Bombardier C, Tugwell PX: Measuring disease-specific quality of life in clinical trials. CMAJ 1986, 134:889-895.

24. Guyatt $G$, Walter $S$, Norman $G$ : Measuring change over time: assessing the usefulness of evaluative instruments. J Chronic Dis 1987, 40:171-178.

\section{Pre-publication history}

The pre-publication history for this paper can be accessed here: http://www.biomedcentral.com/1471-2377/11/48/prepub

doi:10.1186/1471-2377-11-48

Cite this article as: Canafax et al:: Validation of the post sleep questionnaire for assessing subjects with restless legs syndrome: results from two double-blind, multicenter, placebo-controlled clinical trials. BMC Neurology 2011 11:48.

\section{Submit your next manuscript to BioMed Central and take full advantage of:}

- Convenient online submission

- Thorough peer review

- No space constraints or color figure charges

- Immediate publication on acceptance

- Inclusion in PubMed, CAS, Scopus and Google Scholar

- Research which is freely available for redistribution

Submit your manuscript at www.biomedcentral.com/submit
Biomed Central 